\title{
Modeling Triple Solar Still Production Using Jordan Weather Data and Artificial Neural Networks
}

\author{
Mohammad Hamdan $^{a}$, Lubna Badri ${ }^{\mathrm{b}}$ and Eman Abdelhafez ${ }^{\mathrm{a}}$ \\ ${ }^{a}$ Department of Mechanical Engineering, Al-Zaytoonah University of Jordan, Amman, Jordan \\ ${ }^{b}$ Department of Computer and Communication Engineering, Al-Zaytoonah University of Jordan, Amman, Jordan
}

\begin{abstract}
The objective of the study were to assess the sensitivity of the Artificial Mural Networks (ANN) predictions to different combinations of input parameters as well as to determine the minimum amount of inputs necessary to accurately model solar still performance. Satisfactory results for the triple solar still suggest that, with sufficient input data, the ANN method could be extended to predict the performance of other solar still designs in different climate regimes. To accomplish this objective, a study has been performed to determine the effectiveness of triple solar still efficiency ( $\eta$ ) using ANNs. The study used the following parameters as an input to the ANN: time, hourly variation of cover glass temperature $\left(\mathrm{T}_{\mathrm{g}}\right)$, water temperature in the upper basin $\left(\mathrm{T}_{\mathrm{w} 1}\right)$, water temperature in the middle basin $\left(\mathrm{T}_{\mathrm{w} 2}\right)$ and water temperature in the lower basin of the triple basin still $\left(\mathrm{T}_{\mathrm{w} 3}\right)$, distillate volume, ambient temperature $\left(\mathrm{T}_{\mathrm{a}}\right)$, plate temperature $\left(\mathrm{T}_{\mathrm{P}}\right)$ and hourly solar intensity $\left(\mathrm{I}_{\mathrm{s}}\right)$.
\end{abstract}

Keywords: Artificial Neural Network, sensitivity test, Feed forward, Solar Still.

\section{Introduction}

According to the latest estimates of the WHO/UNICEF Joint Monitoring Program for water supply and sanitation (JMP), released in early 2013, 36\% of world's population lack improved sanitation facilities and still use unsafe drinking water. As a result, the researchers motivated their work on other resources like oceans and seas to obtain fresh and clean water by distillation of their water.

Currently the most three commons techniques are: Multi-stage flash distillation (MSF), in which Sea water is distilled by converting a portion of the water into steam in multiple stages of what are essentially countercurrent heat exchangers. Multistage flash distillation plants produce about $60 \%$ of all desalinated water in the world. Multiple-effect distillation (MED), which consists of multiple stages or "effects". In each stage the feed water is heated by steam in tubes. Some of the water evaporates, and this steam flows into the tubes of the next stage, heating and evaporating more water. Each stage essentially reuses the energy from the previous stage. Reverse osmosis (RO), which can remove many types of molecules and ions from solutions and is used in both industrial processes

*Corresponding author. Tel.: +962 795988947

E-mail: eman.abdelhafez@zuj.edu.jo

(c) 2014 International Association for Sharing Knowledge and Sustainability

DOI: $10.5383 /$ ijtee.07.02.005 and in producing potable water. The result is that the solute is retained on the pressurized side of a membrane and the pure solvent is allowed to pass to the other side. All above desalting systems consume energy, either thermal or mechanical or both , RO consumes about $5 \mathrm{kWh} / \mathrm{m} 3$ of mechanical work, while MSF desalting units consume about $4 \mathrm{kWh} / \mathrm{m}^{3}$ pumping energy, besides thermal energy, while The conventional multieffect boiling (MEB) desalting system uses about half of the MSF pumping energy, and almost the same amount of thermal energy used by the MSF, if both have the same gain ratio [1]. Distillation process can be implemented using any heating source. Solar energy is a clean, cheap, and available in plenty at the site. This process removes salts and other impurities. Fortunately, the Jordanian landscape is located within world solar belt and characterized by bright sunshine days around 300-320 days throughout the year.

Santos et al. [2] determine the effectiveness of modeling solar still distillate production using artificial neural networks (ANNs) and local weather data. In their work they used the weather variables affecting solar still performance, which are the daily total insolation, daily average wind velocity, daily average cloud cover, daily average wind direction and daily average ambient temperature. The sensitivity of the ANN predictions is assessed to different combinations of input 
parameters. The computation of the minimum amount of inputs that is needed to model solar still performance is determined. It has been proved that ANN modeling yielded results with up to $78 \%$ of the predictions being within $0-10 \%$, and up to $89 \%$ of the predictions being within $0-20 \%$ of actual distillate production.

Kabeel et al. [3] used stepped basin to improve the performance of solar still. They investigated the influence of depth and width of trays on the performance of the stepped solar still through the use of two solar stills simultaneously. The results showed that maximum productivity of stepped still is achieved at a tray depth $5 \mathrm{~mm}$ and tray width $120 \mathrm{~mm}$, which is about $57.3 \%$ higher than that of the conventional still. Arunkumar et. al. [4] a solar still with a hemispherical top cover for water desalination with and without flowing water over the cover was designed. It is found that daily distillate output of the system was increased by lowering the temperature of the cover by water flowing over it. The efficiency of the still increased from $34 \%$ to $42 \%$ with the top cover cooling effect.

Tanaka [5] presented a basin solar still with a flat plate and external bottom reflector extending from the front wall of the still in addition to the internal. A geometrical model to calculate the direct solar radiation reflected by the external bottom reflector and then absorbed onto the basin liner is proposed. The external reflector can reflect the sunrays to the basin liner and increase distillate productivity. It is found that daily amount of distillate of the still with internal and external bottom reflector is predicted to be $41 \%, 25 \%$ and $62 \%$ greater than that of a conventional basin still on the spring equinox and summer and winter solstices, respectively.

Sing et al. [6] designed and fabricated a modified photovoltaic thermal (PVT) double slope active solar still for remote Locations. The results show that the production rate has been accelerated to 1.4 times than the single slope hybrid (PVT) active solar still for the parallel configuration. The daily average energy efficiency of the solar still is obtained as $17.4 \%$.

A new radiation model for a single-slope solar still was developed in Feilizadeh et. al [ 7 ], which takes into account the effect of all walls of the still on the amount of incident solar radiation on the water surface and each wall. The results show that the effect of the back and side walls is not negligible and they should be taken into consideration to improve the accuracy of the thermal radiation analysis of single-slope solar stills' performance.

Badran and Al-Tahaineh [8] studied the effect of coupling a flat plate solar collector on the productivity of solar stills. Also, in this paper, other different parameters were studied to enhance the productivity such as water depth, direction of still and solar radiation. Single slope solar still with mirrors fixed to its interior sides was coupled with a flat plate collector. It was found that coupling of a solar collector with a still has increased the productivity by $36 \%$. Also the increase of water depth has decreased the productivity, while the still productivity is found to be proportional to the solar radiation intensity.

Al-Hinai et. al. [9] used two mathematical models to compare the productivity of single-effect and double effect solar stills under different climatic, design and operational parameters in Oman. The potential of utilizing an array of single-effect solar stills or double-effect solar stills for the production of drinking water in remote areas in Oman is carried out as a cost analysis study.

Solar stills productivity enhancement have been studied to investigate the performance rating and efficiency of a solar still operating under different conditions. These performances are found experimentally. Due to various measurements and heat transfer processes, experimental part is considered difficult and time consuming. Thus, the development of a mathematical model and numerical prediction for the solar still is very necessary. Traditional simulation codes can be used to estimate the performance of the system, but the algorithms employed are usually complicated and involving solution of complex equations. Therefore, requires large computer power and a considerable long computation time.

Artificial-Neural-Network (ANN) increasingly has been applied for thermal engineering applications. Comparable to the human brain and its learning process, ANN uses connectivity and transfer functions between input, hidden, and output neurons, and successfully has been applied to non-linear systems or systems with unclear dynamics. Different from mathematical models, ANN models have adaptability through a self-tuning process, so can decide accurately without outside expert intervention when unusual disturbances, and/or changes in the process occur. Numbers of studies have been introduced that applied ANN in thermal applications [10-15].

The objectives of the study were to assess the ability of ANN to estimate the performance of a triple basin solar still operating under Jordanian climate. To achieve this, a threelayer feed-forward ANN model was developed to measure the sensitivity of the ANN predictions to different combinations of input parameters as well as to determine the minimum amount of inputs necessary to accurately model solar still performance.

\section{Artificial Neural Network Models}

ANNs consist of layers of interconnected nodes, each node producing a non-linear function of its input. The input to a node may come from other nodes or directly from the input data. Some nodes are identified with the output of the network. The complete network represents a very complex set of interdependencies which may incorporate any degree of nonlinearity, allowing very general functions to be modeled. Supervised neural networks suit prediction problems, where in order to recognize current state previous states have to be considered. These networks keep a track of its k-previous states to build a model that can predict the next state. The supervised ANN used is called multilayer perceptron (MLP), which consists of an input layer, at least one hidden layer, and one output layer, the neurons from each layer being fully connected to the neurons from the next layer. The algorithm used to train this network is called backpropagation algorithm. To develop an ANN model, the input and the desired output is introduced to the ANN. These training sets represent previous recorded measurements of the system under estimation. Then, the network is trained to model the relationship between the input sets and the target outputs. Finally, the testing and verification of the trained network is performed. In this step, an estimating output data are obtained by using unknown input data, which are not used in the training step [16].

The solar still to be tested is that used by Hamdan et.al [17]. It consists of two main parts as shown in Fig. 1. The first part, which is common for all stills used, is the water basin which is made of $1 \mathrm{~mm}$ galvanized steel sheets fabricated in a box shape of $960960150 \mathrm{~mm}^{3}$. The bottom of the box is made of $1.25 \mathrm{~mm}$ black steel. It acts as the absorber plate, such that it absorbs most of the incident solar radiation, most of which will be conducted to the water. The basin of each still is insulated in order to minimize heat losses.

The second part of the still is the condensation surface. In the single basin still, the outside cover of the basin acts as the condensation surface, which consists of four identical 
triangular pieces of $4 \mathrm{~mm}$ thick glass plates. These plates are joined to form a square pyramid with the water basin being its base. Each glass plate is of $950 \mathrm{~mm}$ base and $850 \mathrm{~mm}$ side length. It is to be noted that the condensate surface may be separated from the basin for interior inspection. The joints between the glass plates and the basin were filled by surface silicon (caulk) to eliminate both air infiltration and water vapor escape. Triangular shaped channels were attached to the lower edges of the glass by which the condensate water was meant to be collected.

In the double still, in addition to the outside cover, the glass sheet that forms the upper basin also acts as a condensation surface as water vapor condenses along its lower surface. Further, in the triple basin, the two glass sheets forming the upper and middle basins act as additional condensation surfaces. These sheets are installed at an angle large enough to ensure that the condensate formed on them will flow by gravity to the condensate troughs.

Copper constantun thermocouples were used to measure the temperatures of the water in the basin of each still at several locations to ensure uniform temperature throughout the basin. Also, the temperatures of the inside air and the inside surface of the glass plates were measured for each still. The solar radiation was measured using a Kipp and Zonen 12C Pyranometer,, which was positioned at 328 due south. The mass of condensate water in each still was collected over a certain period of time from which the rate of condensation was measured. The wind speed was measured in front of the still using an anemometer which is connected to a microprocessor from which the wind speed was recorded.

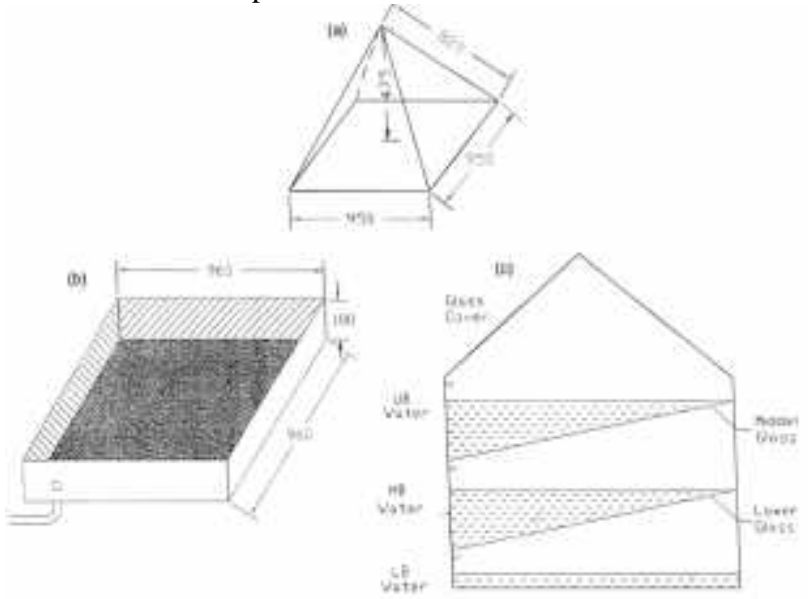

Fig. 1 (a) the lower basin of the three stills. (b) The square base pyramid outer cover for the three stills. (c) Cross sectional view of the triple still.

The metrological data, which was obtained previously from experiments in [17], were used to train the neural network. Three layers network structure is shown in Fig. 1. Nine inputs variables which represent time of hourly variation of cover glass temperature $\left(\mathrm{T}_{\mathrm{g}}\right)$, water temperature in the upper basin $\left(T_{w 1}\right)$, water temperature in the middle basin $\left(T_{w 2}\right)$ and water temperature in the lower basin of the triple basin still $\left(\mathrm{T}_{\mathrm{w} 3}\right)$, distillate volume, ambient temperature $\left(\mathrm{T}_{\mathrm{a}}\right)$, plate temperature $\left(T_{P}\right)$ and hourly solar intensity $\left(I_{s}\right)$ ) are used in training the models of ANNs. One output variable is thermal efficiency ( $\eta$ ) of a triple basin solar still. The neural network models used in this research are described in [18]

MATLAB software is used to design the ANN models and to test the ability of each model to estimate the required efficiency. The performance of the proposed models have been computed and compared using three global statistics: coefficient of determination $\left(\mathrm{R}^{2}\right)$, root mean squared error (RMSE) and mean bias error (MBE). More details about these parameters can be found in [16]. These three parameters are given by:

$$
\begin{aligned}
& R^{2}=1-\frac{\sum_{j}\left(t_{j}-o_{j}\right)^{2}}{\sum_{j}\left(o_{j}\right)^{2}} \\
& R M S E=\sqrt{\frac{\sum_{j}\left(t_{j}-o_{j}\right)^{2}}{p}} \\
& M B E=\frac{\sum_{j}\left(t_{j}-o_{j}\right)}{p}
\end{aligned}
$$

Where:

$t_{j}$ is the target value (desired output),

$\mathrm{o}_{\mathrm{j}}$ is the output value (actual output), and $\mathrm{p}$ is the pattern

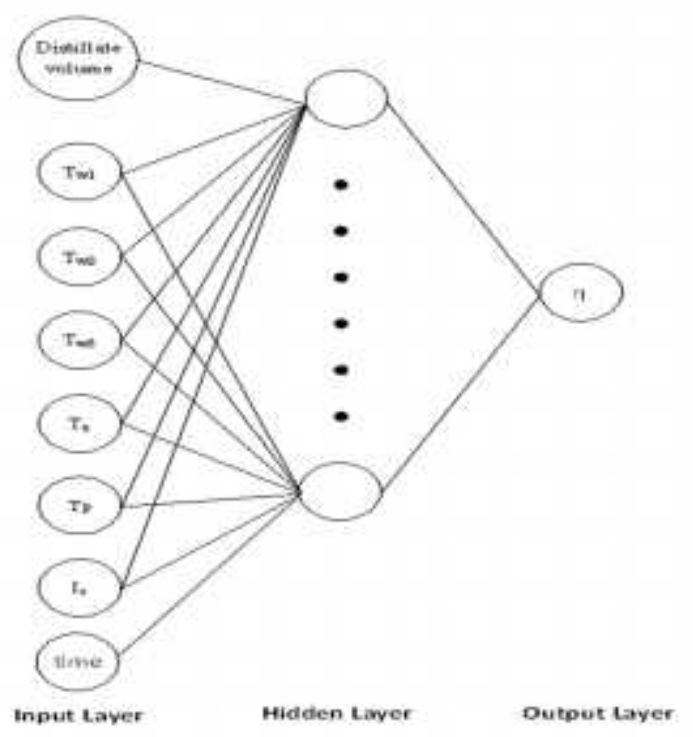

Fig. 2 The architecture of the proposed ANN.

The designed ANN is constructed with 9 neurons in the input layer, 10 neurons in the hidden layer, and one neuron in the output layer. The training set consists of 46 samples obtained from experimental measurements implemented in [17]. The training samples are divided between the training, the validation, and the testing phases of the ANN; such that; $40 \%$ of the data is used for training, 30\% for validation and $30 \%$ for testing. Scaled Conjugate Gradient (trainscg) training algorithm is used. The number of the hidden layer was selected based on trails and errors. Tangent sigmoid function was chosen for the hidden layer neurons and linear transfer function is used in the output layer. The training parameters of the designed ANN are shown in Table1.

The sensitivity tests were performed using six models. Each model designed with different input variables. The aim was to study the effect of specific input parameters on the solar still efficiency. The suggested inputs for each model are shown in table 2. 
Table 1: Training Parameters

\begin{tabular}{|l|c|}
\hline Epochs between displays & 1 \\
\hline $\begin{array}{l}\text { Maximum number of epochs to } \\
\text { train }\end{array}$ & 500 \\
\hline Maximum time to train in seconds & inf \\
\hline Performance goal & 0 \\
\hline Maximum validation failures & 6 \\
\hline $\begin{array}{l}\text { Factor to use for memory/ speed } \\
\text { Tradeoff }\end{array}$ & 1 \\
\hline Minimum gradient error & $1 * 10^{-6}$ \\
\hline
\end{tabular}

Table 2: Models Input

\begin{tabular}{|l|l|}
\hline Model 1 & $\begin{array}{l}\text { Time, Tp, Tw3, Tw2, Tw1, Tg, Ta, Is, Distillate } \\
\text { volume }\end{array}$ \\
\hline Model 2 & Time, Tp, Tw3, Tw2, Tw1, Tg, Ta, Is \\
\hline Model 3 & $\begin{array}{l}\text { Time, Tp, Tw3, Tw2, Tw1, Tg, Ta, Distillate } \\
\text { volune }\end{array}$ \\
\hline Model 4 & Tp, Tw3, Tw2, Tw1, Tg, Ta, Distillate volume \\
\hline Model 5 & Tp, Tw3, Tw2, Tw1, Tg, Ta \\
\hline Model 6 & Tp, Tw3, Tw2, Tw1, Tg, Ta \\
\hline Model 7 & Tp, Tw3, Tw2, Tw1, Tg, Distillate \\
\hline
\end{tabular}

\section{Discussion of Results}

The performance of triple basin solar still operates under Jordanian climate was investigated using Feedforward ANN model.

Figure 3 shows the variation of the gradient error and validation checks at each epoch results produced by the six models. Model 3 trained with the inputs: time, $\mathrm{T}_{\mathrm{p}}, \mathrm{T}_{\mathrm{w} 3}, \mathrm{~T}_{\mathrm{w} 2}$, $\mathrm{T}_{\mathrm{w} 1}, \mathrm{~T}_{\mathrm{g}}, \mathrm{T}_{\mathrm{a}}$, and distillate volume converged faster than other models; where the training stopped after 37 epochs. In Figure 4 , the scatter plots of training, testing, and validation are shown. Figure 3 shows close results for the scatter plot during training, validation, and testing of the experimental data. For Scaled Conjugate Gradient algorithm, it was found that it has the highest values of $\mathrm{R}$ in training, validatiing and testing period for model 3 is given as 0.9997, 0.9993 and 0.99927 respectively.

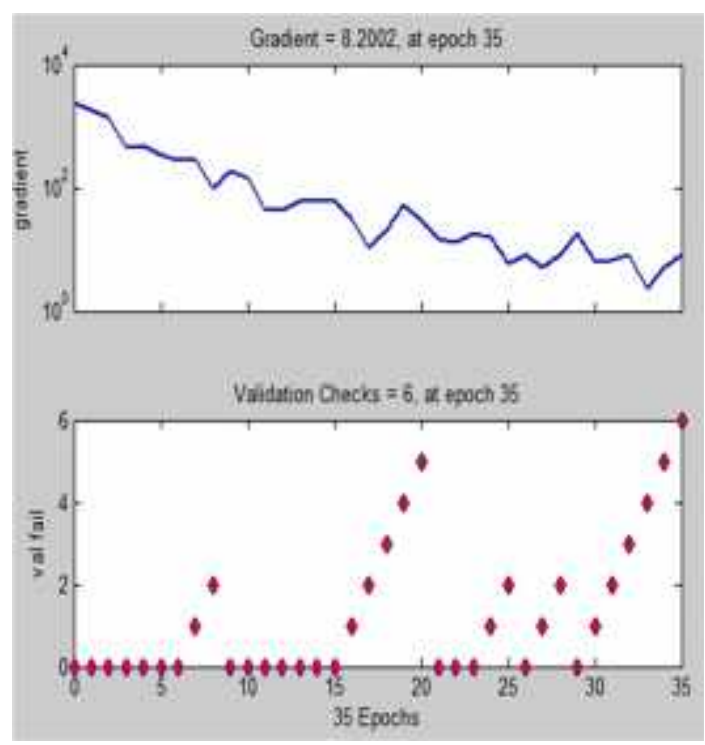

(a)

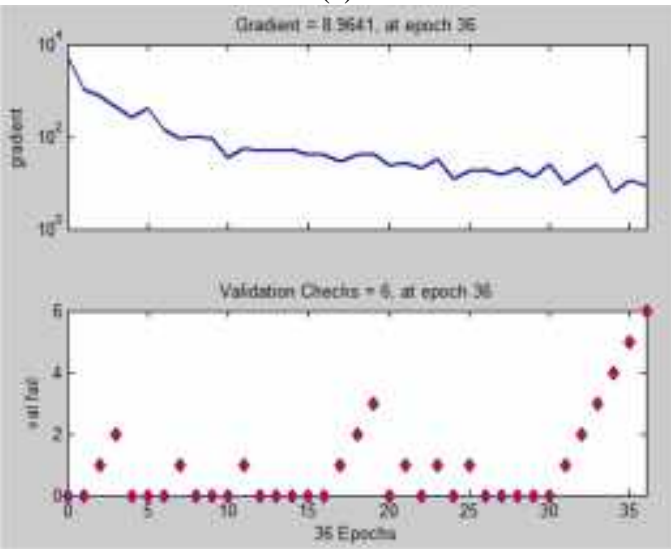

(b)

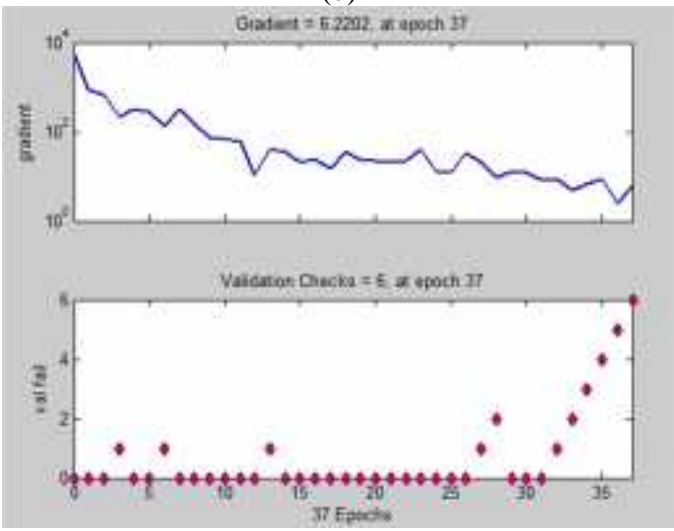

(c) 


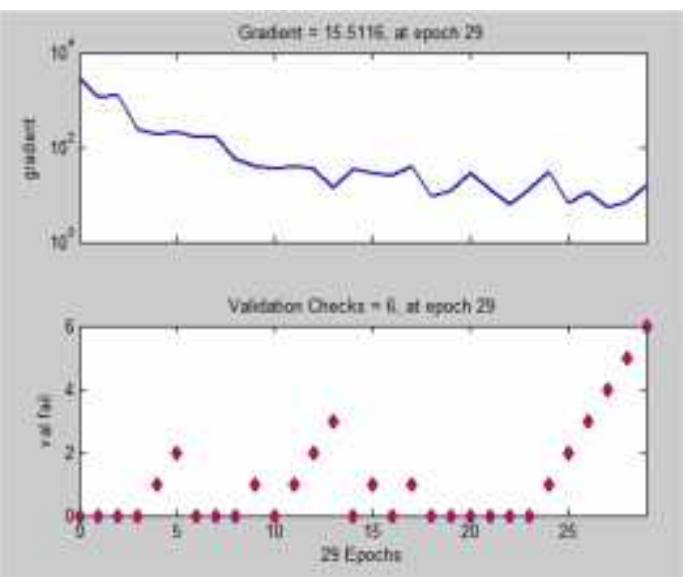

(d)

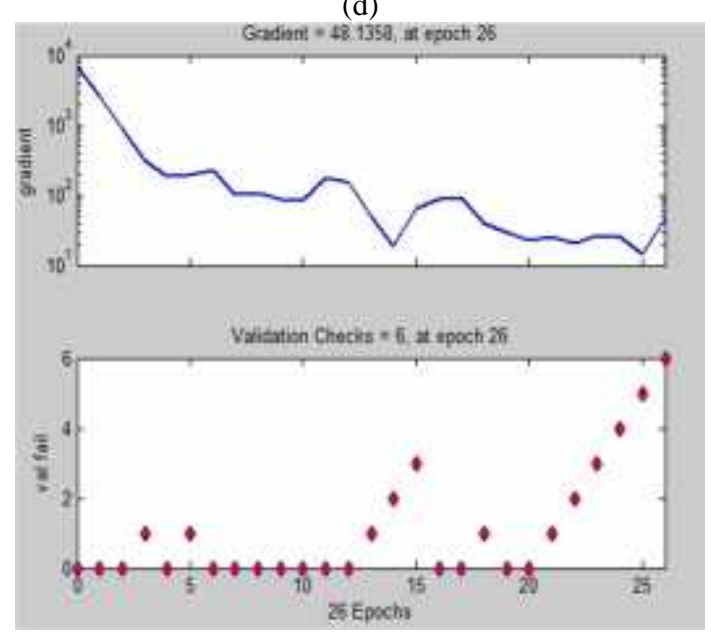

(e)

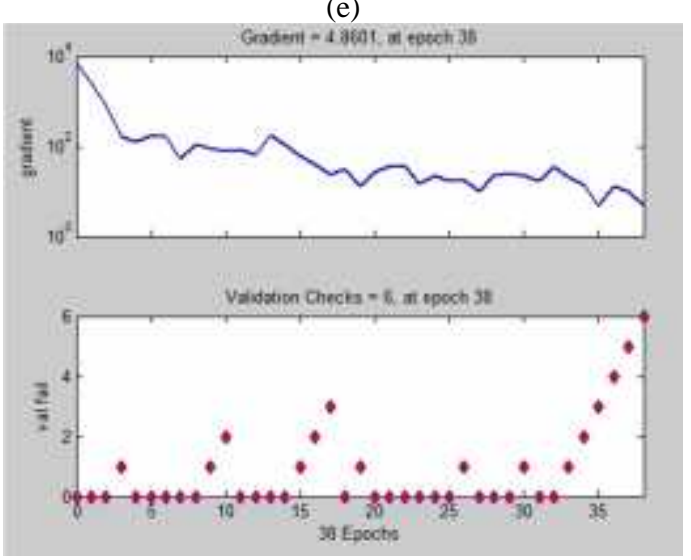

(f)

Fig. 3. Variation of gradient error and validation checks of Feedforward ANN using (a) model 1, (b) model 2, (c) model 3, (d) model 4, (e) model 5, and (f) model 6

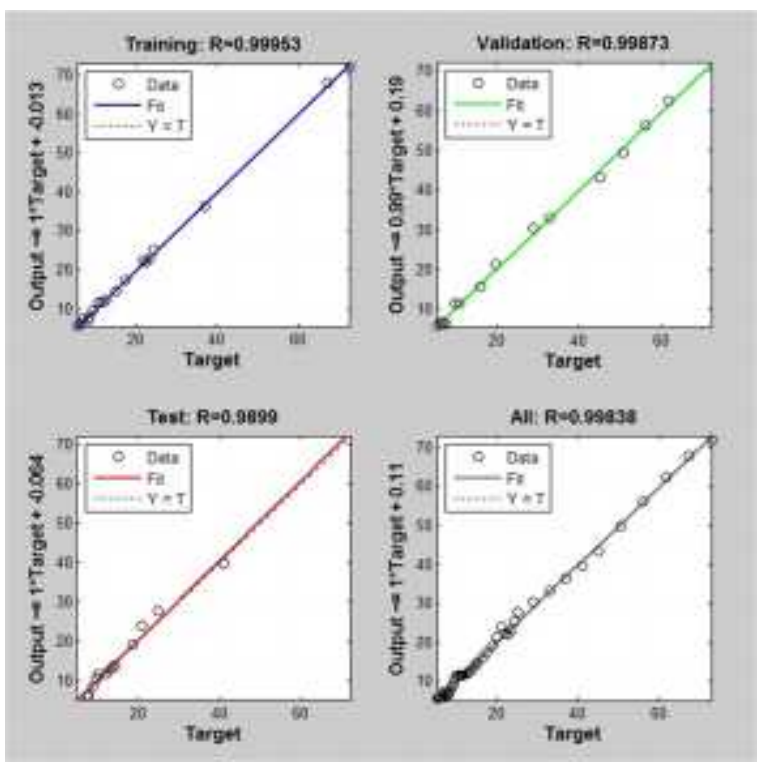

(a)
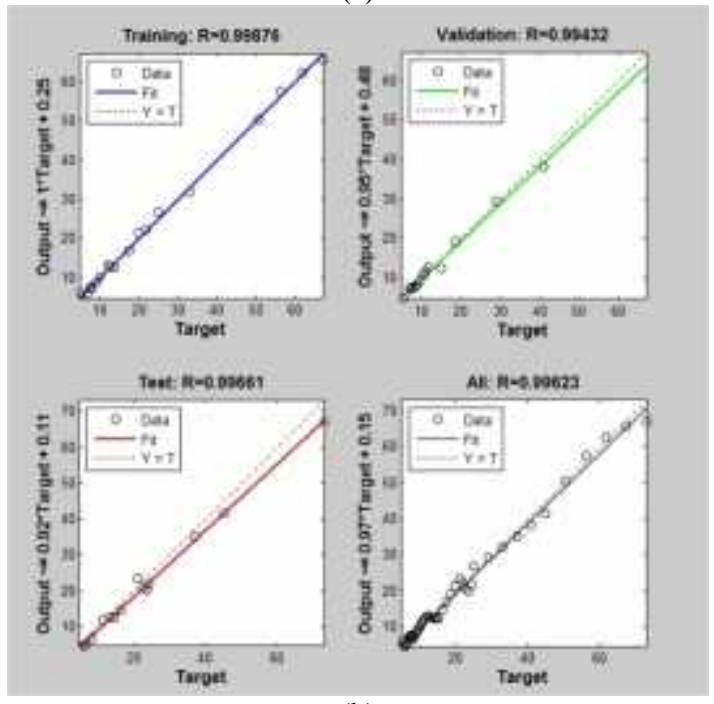

(b)
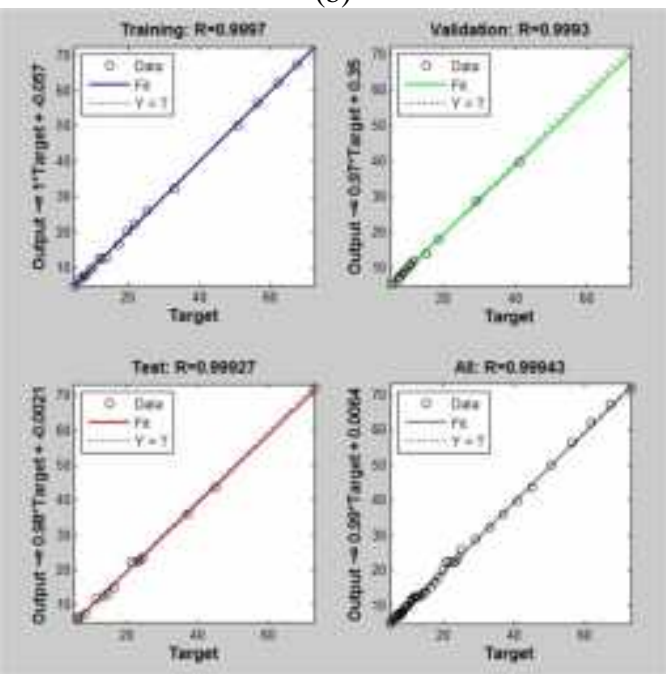

(c) 


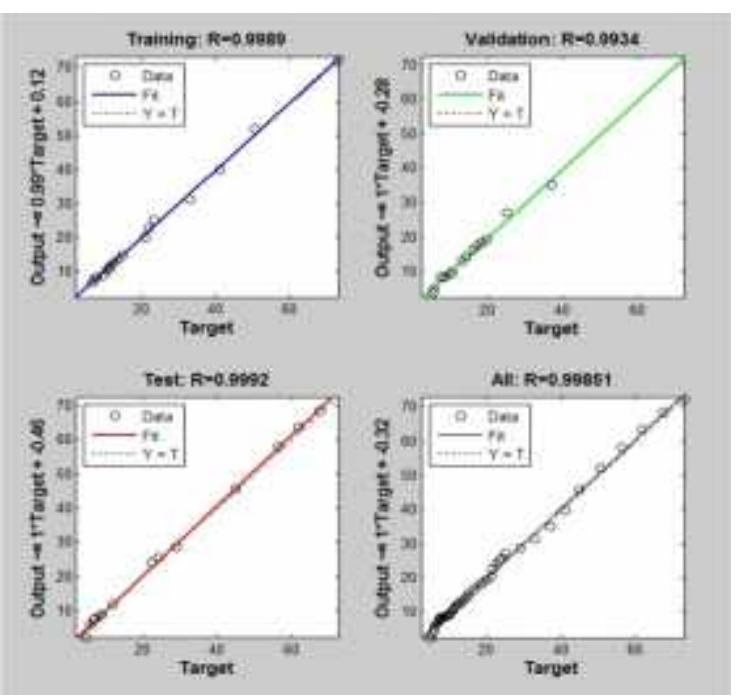

(d)
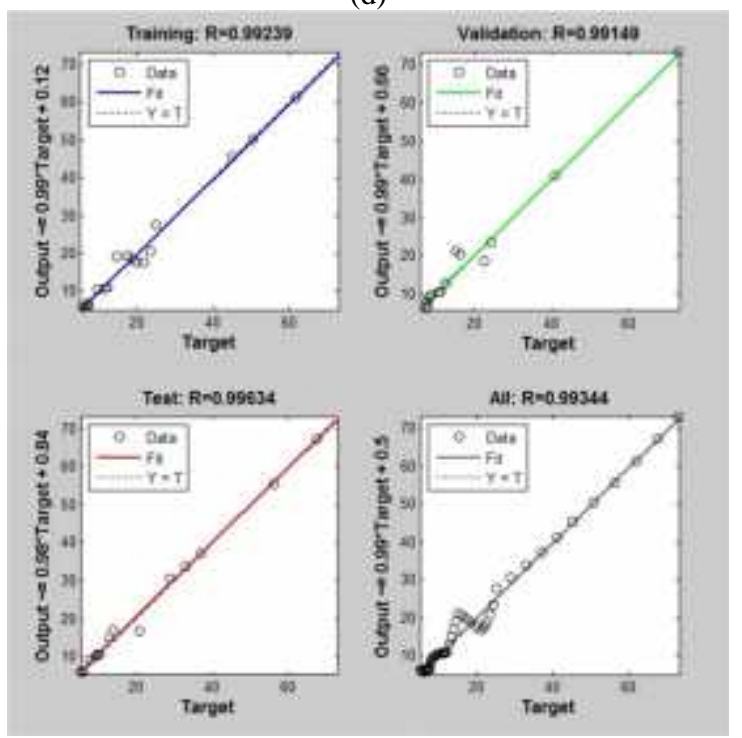

(e)
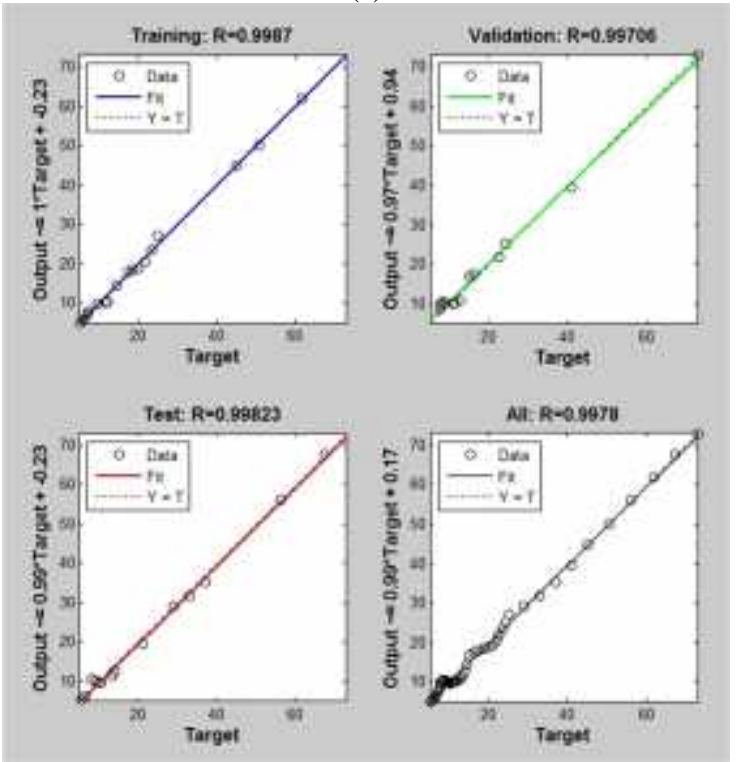

(f)

Fig. 4. Scatter plot of training, validation, testing of all data based Feedforward ANN using (a) model 1, (b) model 2, (c) model 3, (d) model 4, (e) model 5, and (f) model 6
The comparison between the obtained experimental data and the estimated efficiency for the six ANN models are shown in Fig. 5.

Table 3 shows the comparison between the six implemented models. It includes the computed performance results (RMSE, $\mathrm{MBE}$, and R) for these six models. It is clear that model 3 is characterized by more accurate results compared with other models. Consequently, this model may be used to estimate the data with a high accuracy.

Table 3: Comparison of Performance of the Proposed Models

\begin{tabular}{|c|c|c|c|c|c|c|}
\hline & \multicolumn{2}{|c|}{ RMSE } & \multicolumn{2}{c|}{ MBE } & \multicolumn{2}{c|}{$\mathrm{R}$} \\
\cline { 2 - 7 } & $\begin{array}{c}\text { Trainin } \\
\mathrm{g}\end{array}$ & Validation & $\begin{array}{c}\text { Trainin } \\
\mathrm{g}\end{array}$ & $\begin{array}{c}\text { Validati } \\
\text { ou }\end{array}$ & Training & Validation \\
\hline Model 1 & 0.5954 & 0.9825 & 0.5133 & 0.7714 & 0.99953 & 0.99873 \\
\hline Model 2 & 1.0060 & 1.1376 & 0.8380 & 0.7704 & 0.99876 & 0.99432 \\
\hline Model 3 & 0.4904 & 0.4739 & 0.3929 & 0.3375 & 0.9997 & 0.9993 \\
\hline Model 4 & 0.8230 & 0.9881 & 0.6208 & 0.6930 & 0.9989 & 0.9934 \\
\hline Model 5 & 1.9650 & 2.3105 & 1.4233 & 1.4413 & 0.99239 & 0.99149 \\
\hline Model 6 & 0.8348 & 1.4470 & 0.5317 & 1.3316 & 0.9987 & 0.99706 \\
\hline
\end{tabular}

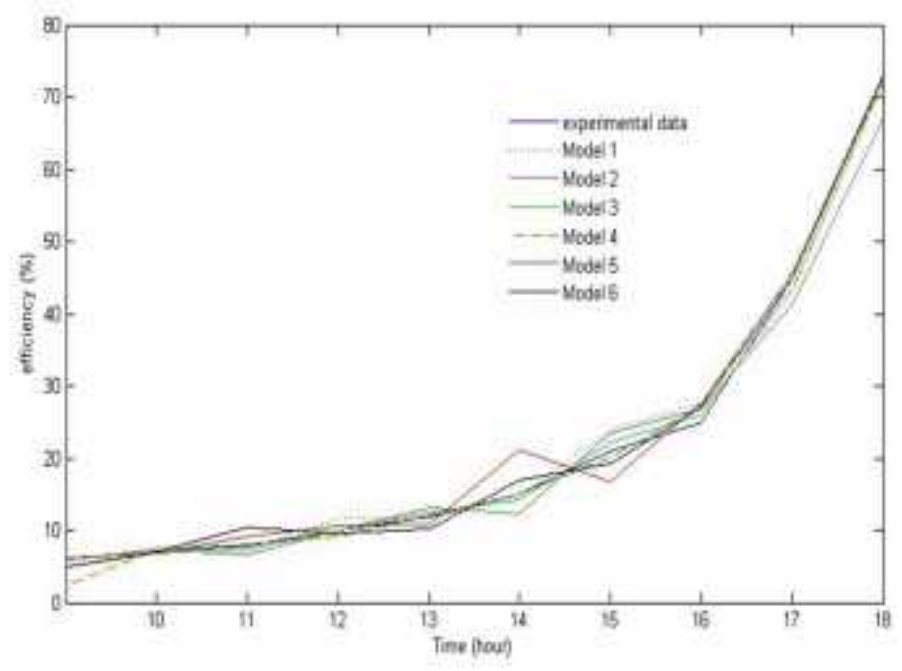

Fig. 5. Comparison between experimental and estimated thermal efficiency.

\section{Conclusion}

In this study, artificial neural network models using trainscg learning algorithm was successfully used to estimate the relation between the efficiency of triple basin solar still and the input variables of solar still.

The comparisons between the estimated data and experimental data showed that ANN models have ability to recognize the relationship between input and output variables. Also the statistical error analysis showed the accuracy of ANN models. On the other hand, the obtained results indicate that feedforward model with time, $\mathrm{T}_{\mathrm{p}}, \mathrm{T}_{\mathrm{w} 3}, \mathrm{~T}_{\mathrm{w} 2}, \mathrm{~T}_{\mathrm{w} 1}, \mathrm{~T}_{\mathrm{g}}, \mathrm{T}_{\mathrm{a}}$, and distillate volume as an input have the best ability for the estimation of the thermal efficiency of the solar still. 


\section{References}

[1] M.A. Darwish, Faisal Al-Juwayhel, Hassan K. Abdulraheim. "Multi-effect boiling systems from an energy viewpoint". Desalination. Volume 194, Issues 1-3, 10 June 2006, Pages 22-39

[2] Santos, N.I., Said, A.M., James, D.E., \& Venkatesh, N.H. (2011). Comparingmultivariate regression and artificial neural networks to model solar still production. Proceedings from American Solar Energy Society: Solar 2011,Raleigh, NC.

[3] A.E. Kabeel, A. Khalil, Z.M. Omara , M.M. Younes (2012). Theoretical and experimental parametric study of modified stepped solar still. Desalination, 289, 12-20.

[4] T. Arunkumar, R. Jayaprakash, D. Denkenberger, Amimul Ahsan, M.S. Okundamiya, Sanjay kumar,Hiroshi Tanaka, H.Ş. Aybar (2011). An experimental study on a hemispherical solar still. Desalination. 286, Pages 342348.

[5] Hiroshi Tanaka (2011). A theoretical analysis of basin type solar still with flat plate external bottom reflector. Desalination, 279, 1-3, 243-251.

[6] Gajendra Singh, Shiv Kumar, G.N. Tiwari (2011), Design, fabrication and performance evaluation of a hybrid photovoltaic thermal (PVT) double slope active solar still, Desalination, 277, 1-3, 15, 399-406.

[7] M. Feilizadeh, M. Soltanieh , K. Jafarpur , M.R. Karimi Estahbanati (2010), A new radiation model for a singleslope solar still. Desalination, 262, Issues 1-3, 166-173.

[8] O.O. Badran, H.A. Al-Tahaineh (2005). The effect of coupling a flat-plate collector on the solar still productivity. Desalination, 183, 137-142

[9] Hilal Al-Hinai, MS. Al-Nassri, B.A. Jubran (2002). Parametric investigation of a double-e eGt solar still in comparison with a single-effect solar still. Desalination, $150,75-83$
[10] Ertunc, H. M., \& Hosoz, M. (2006). Artificial neural network analysis of a refrigeration system with an evaporative condenser. Applied Thermal Engineering, 26, $627-635$

[11] Kalogirou, S. A. (2001). Artificial neural networks in renewable energy systems applications: a review. Renewable and Sustainable Energy Reviews, 5, 373-401.

[12] Kalogirou, S. A. (2006). Prediction of flat-plate collector performance parameters using artificial neural networks. Solar Energy, 80, 248-259.

[13] Mellita, A., \& Kalogirou, S. A. (2008). Artificial intelligence techniques for photovoltaic applications: A review. Progress in Energy and Combustion Science, 34, 574-632.

[14] Sozen, A., Arcaklioglu, E., \& Ozkaymak, M. (2005). Turkey's net energy consumption. Applied Energy, 81, 209-221.

[15] Yang, I. H., Yeo, M. S., \& Kim, K.W. (2003). Application of artificial neural network to predict the optimal start time for heating system in building. Energy Conversion and Management, 44, 2791-2809.

[16] Murat Caner, Engin Gedik, and Ali Keçebas, (2011), Investigation on thermal performance calculation of two type solar air collectors using artificial neural network, Expert Systems with Applications 38, 1668-167.

[17] M.A. Hamdan, A.M. Musa, B.A. Jubran, (1999), Performance of solar still under Jordanian climate, Energy Conversion and Management, Vol. 40, pp. 495-503.

[18] Moghaddamnia, A. , Remesan, R., Hassanpour Kashani, M., Mohammadi, M., Han, D., \& Piri, J.,(2009). Comparison of LLR, MLP, Elman, NNARX and ANFIS Models-with a case study in solar radiation estimation, Journal of Atmospheric and Solar-Terrestrial Physics, 71, 975-982. 